\title{
Mathematical Modelling of Deforestation Due to Population Density and Industrialization
}

\author{
Didiharyono D. ${ }^{1}$, Irwan Kasse ${ }^{2}$ \\ ${ }^{1}$ Andi Djemma University, Palopo, Indonesia \\ ${ }^{2}$ Mathematics, Alauddin State Islamic University Makassar, Indonesia
}

\begin{tabular}{|c|c|}
\hline Article Info & ABSTRACT \\
\hline Article history: & The focus of the study in this paper is to model deforestation due to population density and industrial- \\
\hline Received : 08-21-2021 & ization. To begin with, it is formulated into a mathematical modelling which is a system of non-linear \\
\hline : 10-12-2021 & lifferential equations. Then, analyze the stability of the system based on the Routh-Hurwitz stability \\
\hline Accepted : 10-18-2021 & $\begin{array}{l}\text { criteria. Furthermore, a numerical simulation is performed to determine the shift of a system. The } \\
\text { results of the analysis to shown that there are seven non-negative equilibrium points, which in general }\end{array}$ \\
\hline Keywords: & consist equilibrium point of disturbance-free and equilibrium points of disturbances. Equilibrium point \\
\hline $\begin{array}{l}\text { Mathematical Modelling; } \\
\text { Deforestation; } \\
\text { Population Density; }\end{array}$ & $\begin{array}{l}T E_{7}(x, y, z) \text { analyzed to shown asymptotically stable conditions based on the Routh-Hurwitz stability } \\
\text { criteria. The numerical simulation results show that if the stability conditions of a system have been } \\
\text { met, the system movement always occurs around the equilibrium point. }\end{array}$ \\
\hline
\end{tabular}

Accredited by Kemenristekdikti, Decree No: 200/M/KPT/2020

DOI: https://doi.org/10.30812/varian.v5i1.1412

Corresponding Author:

Didiharyono D.,

Andi Djemma University, Palopo.

Email:muh.didih@gmail.com

This is an open access article under the CC BY-SA license.

\section{A. INTRODUCTION}

Deforestation is a serious problem faced by various countries in the world, including Indonesia. Population density and industrial development have an impact on the forest resources destruction that occurs continuously in the absence of efforts to conserve forest resources. Forest resources are natural resources owned by every country that have an important role in human life. From an economic perspective, forest resources are the largest source of earning foreign exchange, supporting industrial development, and providing employment (Suci and Arnellis, 2014). In terms of balancing the environment, forests have a role in providing water sources, producing oxygen $(\mathrm{O} 2)$ and carbon dioxide (CO2), environmental flora and fauna, including preventing global warming (Wang et al., 2009; Giarno et al., 2020). In addition, forest resources are used as a source of fuel, water storage, recreation areas, industrial raw materials, and others (Ramdhani et al., 2015; Zhang and Wei, 2021).

Indonesia is one of the countries in the world with the largest area of natural forest in the world. The wealth of forest resources causes people to depend on forest resources, such as collecting various types of forest resources to meet their daily needs without destroying them (Agarwal and Pathak, 2015; Anggriani et al., 2018). The population density in recent years has increased. This condition encourages an increase in land needs, both land for housing development, construction of infrastructure, building industrial areas, agriculture, and so on (Sundar et al., 2017). The number of facilities and infrastructure developments has also increased rapidly in line with the increase in population density which has led to increased industrialization (Dubey et al., 2009).

The increase in population and industrialization caused pressure and decreased forest resources (Sebastian and Victor, 2017). This condition will disturb the existence and sustainability of the forest. If it is not carried out in a sustainable and environmentally 
friendly manner, the chances of forest destruction will increase with increasing population density and coupled with poor management of forest resource use in Indonesia (Toaha, 2013; Talumepa, 2020). The extent of forest areas in all major islands in Indonesia is one of the factors supporting the development of the forestry industry. This is because the industry is one of the economic sectors that can become the capital of state income. The industries that are experiencing the fastest growth in the forestry sector are the wood, plywood, and paper industries (Dubey and Narayanan, 2010).

The existence of the timber industry can cause an increase in the demand for wood, the annual industrialization cutting ration, the supply of wood will not be able to be achieved if it only relies on natural forests. So there are allegations, to cover the shortage of wood raw materials, the wood processing industry has logged more than the stipulated quota (Austin et al., 2019). This resulted in decreasing forest area, increasing critical land. If these conditions are left without conservation and conservation activities, most of Indonesia has become an area prone to disasters, both drought, flood and landslides (Ferraro and Simorangkir, 2020).

The problem of forest resource damage caused by population density and industrialization density can model it into a mathematical model (Sundar et al., 2017; Teru and Koya, 2020). The mathematical model used in the mathematical model of forest resource damage in Indonesia is a compartment model. In the compartment model, there are three groups, namely forest resource density, population density and industrialization. Based on the model, it can be seen how the disturbance caused by population density and industrialization which is one of the factors causing damage to forest resources, so that steps can be taken to mitigate forest damage so that it does not occur continuously.

\section{B. LITERATURE REVIEW}

The development of applied mathematics plays an important role in advancing the field of ecology and contributes in modelling ecological problems in an effort to prevent damage to ecosystems including damage to forest resources (Yumna and Halid, 2015; Austin et al., 2019; Qureshi and Yusuf, 2019; Arfan et al., 2021). In connection with the modelling of forest destruction it has been researched by several ecological mathematicians, including (Dubey et al., 2009) studying the problem of the effects of industrialization and population on forests. Then, continue his research by describing a mathematical model regarding the effects of industrialization, human population, and pollution on the reduction of renewable resources. Furthermore, it was carried out (Dubey and Narayanan, 2010) which explained the effect of depletion of forest areas due to increased industrialization on population density pressures or very significant pressure on population growth.

The next study (Misra et al., 2014; Ramdhani et al., 2015) examines the density of industrialization and the addition of controls on industrial density, so that preventive measures are needed on industrial growth through policies or regulations from the government regarding the existence of the industry. Referring to this study (Anggriani et al., 2018) conducted model reconstruction by considering migration factors as population growth which is formulated into a mathematical model and analysed for system stability.

Based on the literature review, the authors reconstructed a model with three compartments, namely forest destruction, population density, and industrialization. In the compartment of forest destruction and population density it is assumed that it grows continuously in the form of a logistical equation by considering the natural damage to forest resources and the presence of migration factors that cause an increase in population. Meanwhile, the industrial compartment takes into account the industrial growth rate and control factors from the government. This problem is formulated in the form of a mathematical model and the stability of the system is analysed around the equilibrium point. The constructed model is expressed in the form of a non-linear differential equation, then its stability is analyzed based on a non-negative equilibrium point by taking into account the Routh-Hurwitz stability criteria. The results of the stability analysis are then performed numerical simulations so that it can be seen the changes in forest resources due to human population density in the presence of the industrial sector.

\section{RESEARCH METHOD}

This research is a basic research which aims to mathematically model deforestation due to population density and industrialization. The method used is the analysis of relevant theories to problems originating from literature studies. The work steps to be taken are reviewing problems on the topic, collecting and linking theories obtained with problems in mathematical models of deforestation, determining assumptions for model formation, linking the relationship between variables in the model with the assumptions that have been made, forming mathematical model of deforestation in Indonesia, analyses the model with the stability theory of the equilibrium point. Analyzing the stability of the equilibrium point, it is necessary to examine the real number part of the eigenvalues of the Jacobian matrix which is negative based on the Routh-Hurwitz stability criterion. The Routh-Hurwitz stability criterion is 
a method used to show the stability of the system by taking into account the coefficients of the characteristic equation without calculating the roots directly. Next, interprets the results of the analysis obtained, numerical simulation with sample parameters from the main reference, and makes conclusions.

\section{RESULT AND DISCUSSION}

\section{Mathematical Modelling}

The formation of a mathematical model of forest resource damage used three variables, namely forest resource density (x), population density (y), and industrialization (z). The assumptions used in the mathematical model analysis of the stability of deforestation due to population density and industrialization are:

a. Density of forest resources and population density is in the form of a logistical equation that is limited by the carrying capacity of the environment.

b. There is natural damage to forest resources caused by natural disasters such as strong winds, landslides, and forest fires.

c. An increase in population due to migration, namely people who come to look for work.

d. The decline in forest resources is the effect of population density, the need for forest resources, and industrialization.

e. The industrial sector is focused on direct utilization of forest resources and other supporting structures.

f. There are efforts to control the government related to operational permits for industrial existence.

Based on the variables, assumptions that have been explained, and the parameters used, a mathematical model diagram of deforestation can be drawn, as in Figure 1:

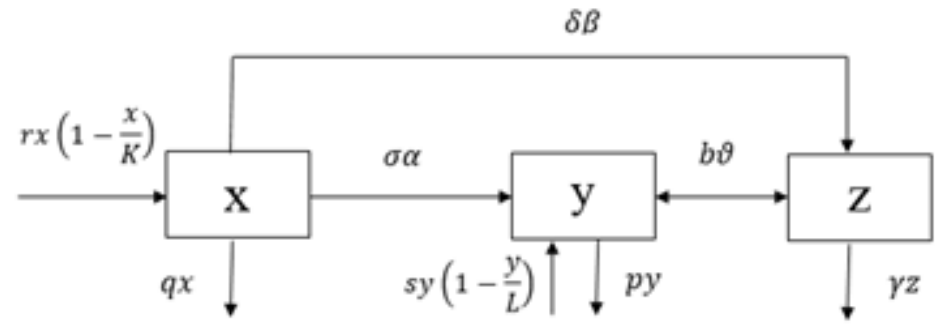

Figure 1. Mathematical Model Diagram of Deforestation

Thus, a mathematical model of forest resource degradation can be formulated as follows:

$$
\begin{aligned}
& \frac{d x}{d t}=r x\left(1-\frac{x}{K}\right)-q x-\alpha x y-\beta x z \\
& \frac{d y}{d t}=s y\left(1-\frac{y}{L}\right)-p y+\sigma \alpha x y+\vartheta y z \\
& \frac{d z}{d t}=\delta \beta x z+b \vartheta y z-\gamma z
\end{aligned}
$$

Where,

\begin{tabular}{clc}
\hline Parameter & Explanation & Dimension \\
\hline$r$ & Natural growth rate of forest resources & $(\text { Year })^{-1}$ \\
$s$ & Population growth rate & $(\text { Year })^{-1}$ \\
$K$ & Carrying capacity of forests & Biomass \\
$L$ & Carrying capacity of the population & Biomass \\
$q$ & The rate of natural destruction of forest resources & $(\text { Year })^{-1}$ \\
$\alpha$ & The rate of deforestation due to increasing population density & $(\text { Year })^{-1}$ \\
$\beta$ & The rate of deforestation due to industrialization & $(\text { Year })^{-1}$ \\
$\mathrm{p}$ & Natural population mortality rate & $(\text { Year })^{-1}$ \\
$\sigma$ & The rate of population growth is due to the existence of forest resources that support life & $(\text { Year })^{-1}$ \\
$\vartheta$ & Population growth rate due to population migration & $(\text { Year })^{-1}$ \\
$b$ & The number of people who work in industry & $(\text { Year })^{-1}$ \\
$\delta$ & The industrial growth rate is due to the increasing population density & $(\text { Year })^{-1}$ \\
$\gamma$ & Control coefficient of industrialization control by the government & $(\text { Year })^{-1}$ \\
\hline
\end{tabular}


The model is expressed in a non-linear differential equation, which fulfils the initial conditions of each positive variable where $x(0) \geq 0, y(0) \geq 0$, and $z(0) \geq 0$ (Anggriani et al., 2018).

\section{Model Analysis}

Based on the analysis carried out on model (1), in general there are two types of balance points, namely the equalibrium point of disturbances-free and the equalibrium point of disturbance. The equalibrium point of disturbance-free is defined as a condition where there is no damage to forest resources caused by population density and industrialization density. Meanwhile, the equalibrium point of disturbance is defined as a condition of ddeforestation caused by exploitation by the population and industrialization (Suci and Arnellis, 2014). Thus, the analysis of model (1) obtained seven non-negative equalibrium points, namely as follows.

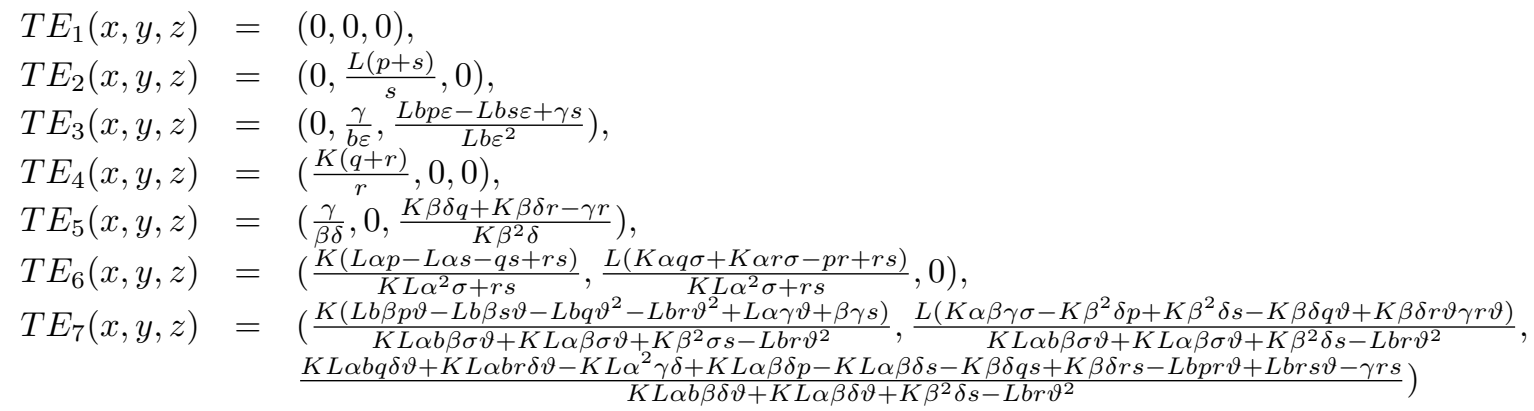

And can be simplified to,

$$
T E_{7}(x, y, z)=\left(\frac{K(L b E+L \alpha \gamma \vartheta+\beta \gamma s)}{F}, \frac{L(K \beta G-\gamma r \vartheta)}{F}, \frac{K L H-K \beta I-L b J-\gamma r s}{F}\right)
$$

Where, $E=\beta p \vartheta-\beta s \vartheta-q \vartheta^{2}-r \vartheta^{2}, F=K L \alpha b \beta \delta \vartheta+K L \alpha \beta \delta \vartheta+K \beta^{2} \delta s-L b r \vartheta^{2}, G=\alpha \gamma \sigma-\beta \delta p+\beta \delta s-\delta q \vartheta+\delta r \vartheta$, $H=\alpha b q \delta \vartheta+\alpha b r \delta \vartheta-\alpha^{2} \gamma \delta+\alpha \beta \delta p-\alpha \beta \delta s, I=\delta q s+\delta r s$, and $J=p r \vartheta+r s \vartheta$ is a positive parameter.

The Equalibrium points of disturbance-free obtained are points $T E_{1}(x, y, z)$ and $T E_{4}(x, y, z)$, which is a condition in which forest resources always grow continuously (naturally) without any disturbance and grow as much as the carrying capacity of their environment, namely $\frac{K(q+r)}{r}$. Meanwhile, the equilibrium point with the disturbance obtained is the points $T E_{2}(x, y, z), T E_{3}(x, y, z), T E_{5}(x, y, z), T E_{6}(x, y, z)$, and $T E_{7}(x, y, z)$. The equilibrium point $T E_{2}(x, y, z)$ shows that the rate of forest resources has not changed, there is an effect of population density on the system with the condition $L(p+s)>0$, without being influenced by the existence of industrialization.

The equalibrium $T E_{3}(x, y, z)$ show that the rate of forest resources has not changed, there is an effect on the population density of the system with condition $\gamma>0$ and the influence of industrialization on condition $L b(p \vartheta-s \vartheta)>0$. The equalibrium $T E_{5}(x, y, z)$ show that the rate of forest resources experiencing changes with condition $\gamma>0, \beta \delta 0$, the effect of population density does not exist on the system and there is an effect of industrialization with condition $K \beta(\delta q+\delta r)>0$. Meanwhile, the equalibrium point $T E_{6}(x, y, z)$ show the rate at which forest resources are changing, there is an effect of population density and there is no influence of industrialization on the system. The equilibrium point in model (2) is a balance point where forest resources are damaged due to population density and industrialization. This is indicated by the equilibrium point $T E_{7}(x, y, z)$ which will then be analyzed for the stability of the system.

Analysis of the stability of the equilibrium point is obtained by determining the eigenvalues of the Jacobian matrix from model (1). Meanwhile, for the Jacobian matrix from model (1) it is obtained as follows:

$$
J=\left(\begin{array}{ccc}
r-\frac{2 r x}{K}-q-\alpha y-\beta z & -\alpha x & -\beta x \\
\sigma \alpha y & s-\frac{2 s y}{K}-p-\sigma \alpha x+\vartheta z & \vartheta y \\
\beta \delta z & b \vartheta z & b \vartheta y+\beta \delta x-\gamma
\end{array}\right)
$$

Furthermore, the characteristic equation of the Jacobian matrix will be determined by calculating, $\operatorname{det}(J-\lambda I)=0$. By assuming $u=r-\frac{2 r x}{K}-q-\alpha y-\beta z, v=s-\frac{2 s y}{K}-p-\sigma \alpha x+\vartheta z$, and $w=b \vartheta y+\beta \delta x-\gamma$ then it can be written.

$$
\lambda I-J=\left(\begin{array}{ccc}
\lambda-u & -\alpha x & -\beta x \\
\sigma \alpha y & \lambda-v & \vartheta y \\
\beta \delta z & b \vartheta z & \lambda w
\end{array}\right)
$$


Based on the calculation and analysis of equation (3), the characteristic equation is obtained,

$$
\begin{aligned}
& \lambda^{3}+(u+v+w) \lambda^{2}+\left(b \beta \vartheta x y z+\alpha^{2} \sigma x y+b y z \vartheta^{2}+\beta^{2} \delta x z+u v+u w+v w\right) \lambda+\alpha \beta \sigma x y z \vartheta+\alpha^{2} \sigma w x y+b u y z \vartheta^{2}- \\
& \beta^{2} \delta v x z-u v w=0 .
\end{aligned}
$$

And it can be written in equation $f(\lambda)=\lambda^{3}+a_{2} \lambda^{2}+a_{1} \lambda+a_{0}$, with

$a_{0}=\alpha \beta \sigma x y z \vartheta+\alpha^{2} \sigma w x y+b u y z \vartheta^{2}-\beta^{2} \delta v x z-u v w$

$a_{1}=b \beta \vartheta x y z+\alpha^{2} \sigma x y+b y z \vartheta^{2}+\beta^{2} \delta x z+u v+u w+v w$,

$a_{2}=-u-v-w$.

Based on the analysis carried out that the point of balance $T E_{7}(x, y, z)$ asymptotically stable, because it meets the RouthHurwitz stability criteria where $a_{0}>0, a_{2}>0$, and $a_{2} a_{1}-a_{0}>0$ (Didiharyono, 2016). This will be demonstrated in the following numerical simulation.

\section{Numerical Simulation}

This simulation aims to identify things that might happen to system dynamics and system changes. For this reason, giving the parameter values used in model (1) is done by modifying the parameter values in (Dubey and Narayanan, 2010; Anggriani et al., 2018), namely $K=40 ; r=24 ; q=0.5 ; \alpha=1.2 ; \beta=1.5 ; s=11 ; L=50 ; p=10 ; \sigma=0.01 ; \vartheta=0.02 ; b=0.01$; $\delta=1.5$; and $=0.5$. This parameter is used to determine the equilibrium point of the model (1). Based on the analysis, there are seven equalibrium points of positive, namely $T E_{1}(x, y, z)=(0,0,0), T E_{2}(x, y, z)=(0,2500,27450), T E_{3}(x, y, z)=$ $(0,4.5454,0), T E_{4}(x, y, z)=(39.1667,0,0), T E_{5}(x, y, z)=(0.2222,0,15.5778), T E_{6}(x, y, z)=(27.1174,6.0245,0)$, and $T E_{7}(x, y, z)=(0.2217,5.5687,11.1229)$. The equilibrium point $T E_{7}(x, y, z)$ stability will be analyzed because each compartment is non-negative. This means that forest resources are being damaged due to population density and industrialization around forest areas protected by the state. Then, analyze the stability of the equilibrium point $T E_{7}(x, y, z)$ by linearizing the model (1) using the Jacobian matrix,

$$
J=\left(\begin{array}{ccc}
-0.1160 & -0.264 & -0.330 \\
0.06672 & -1.2213 & 0.1112 \\
25.0200 & 0.002224 & -0.00388
\end{array}\right)
$$

So that the characteristic equation is obtained $f(\lambda)=\lambda^{3}+1.3412 \lambda^{2}+8.4208 \lambda+10.8194$ with eigenvalues $\lambda_{1}=$ $-0.0235+2.8912(I) ; \lambda_{2}=-0.0235-2.8912(I)$; and $\lambda_{3}=-1.2941$ because the value of lamda $(\lambda)$ all are negative and based on the Routh-Hurwiz stability criteria $a_{0}>0(10.8194>0), a_{2}>0(1.3412>0)$, and $a_{2} a_{1}-a_{0}>0(1.3412 *$ $8.4208-10.8194>0)$ then the equalibrium point $T E_{7}(x, y, z)$ asymptotically stable (Toaha and Rustam, 2017; Didiharyono and Irwan, 2019).

The following figure shows that the stability of the solution curve of the predator prey population against time $(t)$, is around the equilibrium point for the initial value around the equilibrium point $x(0)=0.2217, y(0)=5.5687$, dan $z(0)=11.1229$.

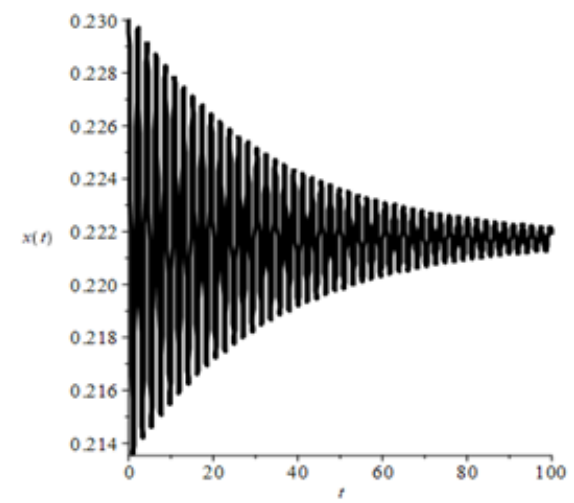

Figure 2. Behavior of Curve Solution for Forest Resource Compartment

The graph in Figure 2 shows that the growth rate of forest resources has increased then decreased around its equilibrium point. The condition of the balance of forest resources is strongly influenced by the parameter values of $\alpha$ and $\beta$. Using 
the above parameters, regardless of the initial value given, the solution for the forest resource compartment curve will remain stable around the equilibrium point. This means that the condition of forest resource degradation due to population density and industrialization will be controlled or remain stable.

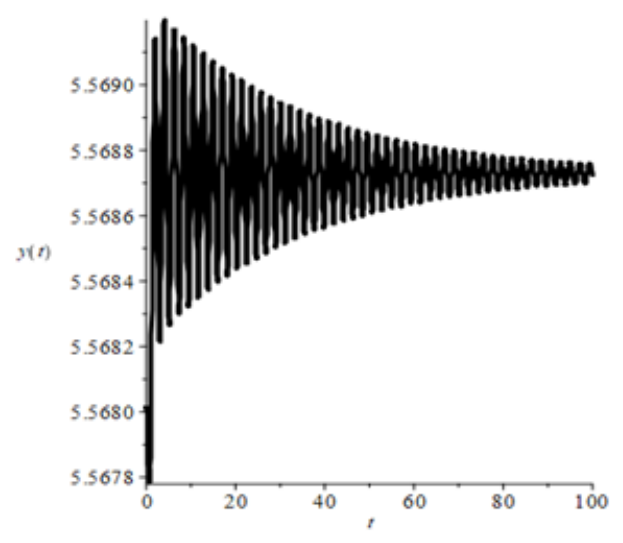

Figure 3. Behavior of Curve Solution for Population Density Compartment

The graph in Figure 3 shows that the population density rate has increased then decreased around the equilibrium point. The equilibrium condition for the population density compartment is influenced by the parameter values $\alpha$ and $\vartheta$. By using the above parameters, no matter how big the initial value is given, the solution of the population density compartment curve will remain stable around the equilibrium point.

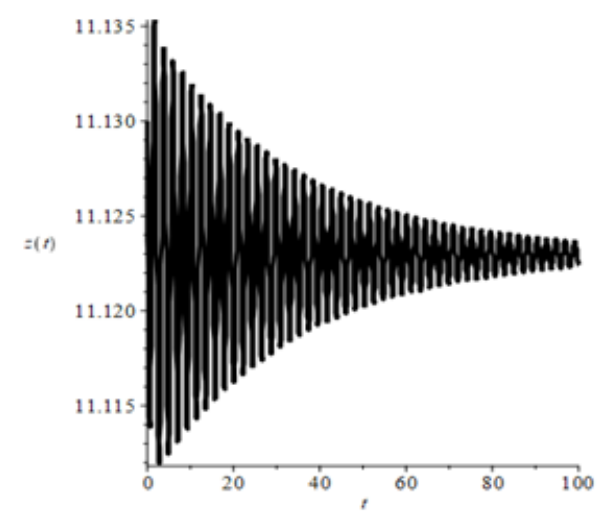

Figure 4. Behavior of Curve Solution for Industrialization Compartment

The graph in Figure 4 shows that the compartment of industrialization has increased then decreased around its equilibrium point. The equilibrium condition for the existence of industrialization is strongly influenced by the parameter values $\beta$ and $\vartheta$. Using the above parameters, regardless of the initial value given, the industrialization compartment curve solution will remain stable around the equilibrium point.

It is common knowledge that when the population density occurs, there will be an increase in the use of forest resources which are used for the needs of the community. If the rate of utilization of forest resources is greater than the rate of growth of forest resources, it will result in imbalances in the use of forest resources and also have an impact on the deforestation. Furthermore, the development of industrialization in the use of forest resources also results in deforestation. If the rate of utilization of forest resources by industry is greater than the control and operational permits from the government, it will result in unstable conditions, an imbalance in the environment, and deforestation. If that happens, it can cause disasters that threaten the survival of human life and the lives of other creatures.

One of the ways that can be done to reduce forest damage is by increasing control in the use of forest resources, so that it can become a major concern for all parties in protecting forest resources. The main activity that can be carried out is by means of reforestation so that forest resources are sustainable and sustainably maintained. Not only that, there is also a need for strict 
supervision of the use of forest resources from the government and legal action for violations committed in the use of forest resources, including abuse of authority that has harmed the state (Kartodihardjo, 2017).

\section{E. CONCLUSION AND SUGGESTION}

Based on the analysis and previous discussion, it can be concluded that the increase in population density and industrialization has led to a decrease in forest resources which has an impact on deforestation. The results of the analysis of the mathematical model show that there are seven non-negative equalibrium points, which in general consist equilibrium point of disturbance-free and equilibrium point of disturbances. The equalibrium point $T E_{7}(x, y, z)$ analyzed showed asymptotically stable conditions based on the Routh-Hurwitz stability criteria. Based on the numerical simulation results, it shows that if the system stability conditions have been met, the system movement always occurs around the equilibrium point. In order for forest resources to be sustainable and their existence maintained, it is necessary to replant forest resources (reforestation) that have been used. Furthermore, strict supervision or control and legal enforcement from the government is needed as a sanction for damage to forest resources.

\section{REFERENCES}

Agarwal, M. and Pathak, R. (2015). Conservation of Forestry Biomass and Wildlife Population: A Mathematical Model. Asian Journal of Mathematics and Computer Research, 4(1):1-15.

Anggriani, I., Nurhayati, S., and Subchan, S. (2018). Analisis Kestabilan Model Penurunan Sumber Daya Hutan Akibat Industri. Limits: Journal of Mathematics and Its Applications, 15(1):31-40.

Arfan, A., Maru, R., Side, S., Abidin, M. R., and Sideng, U. (2021). Mangrove Forest Management Strategy As A Sustainable Production Forest Area in Luwu District, South Sulawesi Province, Indonesia. Journal of Physics: Conference Series, 1752(1).

Austin, K. G., Schwantes, A., Gu, Y., and Kasibhatla, P. S. (2019). What Causes Deforestation in Indonesia? Environmental Research Letters, 14(2):024007.

Didiharyono, D. (2016). Stability Analysis of One Prey Two Predator Model with Holling Type III Functional Response and Harvesting. Journal of Math Sciences, 1(2):50-54.

Didiharyono, D. and Irwan, M. (2019). Analisis Kestabilan dan Usaha Pemanenan Model Predator Prey Tipe Holling III dengan Keuntungan Maksimum. Jurnal Varian, 2(2):55-61.

Dubey, B. and Narayanan, A. S. (2010). Modelling Effects of Industrialization, Population and Pollution on a Renewable Resource. Nonlinear Analysis: Real World Applications, 11(4):2833-2848.

Dubey, B., Sharma, S., Sinha, P., and Shukla, J. B. (2009). Modelling The Depletion of Forestry Resources By Population and Population Pressure Augmented Industrialization. Applied Mathematical Modelling, 33(7):3002-3014.

Ferraro, P. J. and Simorangkir, R. (2020). Conditional Cash Transfers to Alleviate Poverty also Reduced Deforestation in Indonesia. Science Advances, 6(24):1-8.

Giarno, G., Didiharyono, D., Fisu, A. A., and Mattingaragau, A. (2020). Influence Rainy and Dry Season to Daily Rainfall Interpolation in Complex Terrain of Sulawesi. In IOP Conference Series: Earth and Environmental Science, page 012003.

Kartodihardjo, H. (2017). Dibalik Krisis Ekosistem: Pemikiran Tentang Kehutanan dan Lingkungan Hidup.

Misra, A. K., Lata, K., and Shukla, J. B. (2014). A Mathematical Model for The Depletion of Forestry Resources Due to Population and Population Pressure Augmented Industrialization. International Journal of Modeling, Simulation, and Scientific Computing, 5(01):1350022.

Qureshi, S. and Yusuf, A. (2019). Mathematical Modeling for The Impacts of Deforestation on Wildlife Species Using Caputo Differential Operator. Chaos, Solitons \& Fractals, 126(1):32-40.

Ramdhani, V., Jaharuddin, J., and Nugrahani, E. H. (2015). Dynamical System of Modelling The Depletion of Forestry Resources Due to Crowding By Industrialization. Appl. Math. Sci, 9(82):4067-4079. 
Sebastian, E. and Victor, P. (2017). Modelling Deforestation Due to Human Population and Its Effect on Farm Fields. Journal of Informatics and Mathematical Sciences, 9(3):903-913.

Suci, N. and Arnellis, A. (2014). Model Matematika Kerusakan Sumber Daya Hutan di Indonesia. UNP Journal of Mathematics, 1(1):1-6.

Sundar, S., Swaroop, N., and Naresh, R. (2017). Modeling The Effect of Population and Population Augmented Industrialization on Forestry Resources. European Journal of Engineering Research and Science, 2(1):65-70.

Talumepa, J. B. (2020). Kajian Hukum Terhadap Tata Kelola Hutan di Indonesia. Lex Et Societatis, 8(4):25-35.

Teru, A. H. and Koya, P. R. (2020). Mathematical Modelling of Deforestation of Forested Area Due to Lack of Awareness of Human Population and Its Conservation. Mathematical Modelling and Applications, 5(2):94.

Toaha, S. (2013). Pemodelan Matematika dalam Dinamika Populasi.

Toaha, S. and Rustam, R. (2017). Optimal Harvesting Policy of Predator-Prey Model with Free Fishing and Reserve Zones. In AIP Conference Proceedings, page 020023.

Wang, J., Chagnon, F. J., Williams, E. R., Betts, A. K., Renno, N. O., Machado, L. A., ..., and Bras, R. L. (2009). Impact of Deforestation in The Amazon Basin on Cloud Climatology. Proceedings of the National Academy of Sciences, 106(10):36703674.

Yumna, Y. and Halid, I. (2015). Special Analysis for Predicting Changes In Mangrove Forest. International Journal of Scientific \& Technology Research, 4(1):144-147.

Zhang, M. and Wei, X. (2021). Deforestation, Forestation, and Water Supply. Science,, 371(6533):990-991. 